\title{
DIMENSIONAMENTO E GESTÃO DE RESERVATÓRIOS: BREVE DISCUSSÃO ACERCA DA EXPERIÊNCIA DO ESTADO DO CEARÁ/BRASIL
}

\author{
Sizing and management of reservoirs: brief discussion about the experience of the state of \\ Ceará/Brazil
}

Sulivan Pereira Dantas ${ }^{1}$ https://orcid.org/0000-0002-4615-1168

1 Doutor em Geografia - UFC. Professor de Geografia - Prefeitura Municipal de Fortaleza. E-mail:
sulivandantas@yahoo.com.br

\begin{abstract}
Resumo
O presente trabalho tem como objetivo discutir a contribuição do processo de açudagem para o desenvolvimento do Nordeste brasileiro e apresentar elementos fundamentais que compõem a dinâmica de gestão de reservatórios no estado do Ceará. O processo de açudagem foi e é a política de acesso a água, predominante, no Nordeste do Brasil. Isso traz em pauta as discussões sobre modelos de redimensionamento de águas e eficiência no gerenciamento de açudes. Neste trabalho, além desta discussão, foi proposto um mapeamento de classificação dos maiores açudes cearenses por capacidade volumétrica.
\end{abstract}

Palavras-chave: Açudes; Semiárido; Classificação de reservatórios.

\begin{abstract}
This paper aims to discuss the contribution of açudagem process for the development of the Brazilian Northeast and present key elements that make up the reservoir management dynamics in the state of Ceará. The açudagem process was and is the policy of access to water, predominantly in the Northeast of Brazil. This brings on the agenda discussions on water resizing models and efficient management of dams. In this work, in addition to this discussion, it was proposed a classification mapping of the largest dams of Ceará volumetric capacity.
\end{abstract}

Keywords: Dams; semiarid; reservoirs rating. 
Dimensionamento e gestão de reservatórios: breve discussão acerca da experiência do estado do Ceará/Brasil

Sulivan Pereira Dantas

\section{INTRODUÇÃO}

Compreender a problemática dos recursos hídricos nas regiões semiáridas é uma questão fundamental para superação dos obstáculos ao desenvolvimento. É nítido que a política de construção de infraestruturas capazes de armazenar água para garantir o abastecimento humano e animal e viabilizar a irrigação é a mais utilizada no mundo. Todavia, esse esforço não exime a população de continuar a vivenciar alta vulnerabilidade a disponibilidade hídrica, em situações de eventos extremos de seca. De qualquer modo, essas políticas com adequada gestão viabilizam critérios essenciais para o desenvolvimento.

Nesse contexto, o Nordeste do Brasil se caracteriza como um importante objeto de estudo para as questões levantadas, pois, apresenta alta vulnerabilidade quanto à disponibilidade de água regular, impactando na distribuição e acesso a água e consequentemente no desenvolvimento socioeconômico regional. Para que o uso dos reservatórios seja sustentável é necessário que ocorra planejamento adequado ao contexto da região que receberá a construção dessas barragens e um gerenciamento qualitativo e quantitativo após sua instalação. A intenção do processo de açudagem é proporcionar o desenvolvimento da região através da disponibilidade hídrica para as atividades agrícolas, industriais e serviços, e principalmente, ao abastecimento humano.

$\mathrm{O}$ objetivo deste trabalho é discutir quanto à eficiência das barragens e como o processo de gestão influencia na vida útil e na sustentabilidade dos reservatórios no estado do Ceará.

\section{MATERIAIS E MÉTODOS}

Este trabalho conta com discussão teórica sobre a política de redimensionamento das águas superficiais do estado do Ceará de acordo com a política de açudagem empregada no estado, tendo como ênfase a discussão do gerenciamento dos reservatórios monitorados pelos órgãos responsáveis.

Após a discussão sobre a conjuntura do gerenciamento dos reservatórios, é proposto um mapa dos reservatórios de macro e de grande porte do estado do Ceará, tomando como base os açudes monitorados pela Companhia de Gestão dos Recursos Hídricos do Ceará (COGERH).

\section{RESULTADOS E DISCUSSÕES}

É evidente que a discussão sobre a política de açudagem perpassa pela escolha do dimensionamento dos reservatórios e suas implicações sobre a organização socioambiental da região de influência. Portanto, faz-se necessário apresentar a dinâmica da construção destes 
Dimensionamento e gestão de reservatórios: breve discussão acerca da experiência do estado do Ceará/Brasil

Sulivan Pereira Dantas

reservatórios e discutir de que maneira esses fatores interferem na dinâmica da paisagem local, na organização da sociedade do entorno e das consequências ao meio ambiente.

\section{A política de dimensionamento dos reservatórios e a conjuntura do gerenciamento}

A partir das duas vertentes de convivência com a seca, a estruturante e a emergencial, a política de construção de reservatórios destaca-se como a obra estruturante mais consolidada no estado do Ceará. Porém, abre espaço para um debate que se propõe a discutir a dimensão dos reservatórios e sua eficiência.

Portanto, qual a dimensão do açude seria mais eficiente no contexto do semiárido: os açudes de pequeno ou de grande porte? Essa questão já levou a inúmeras discussões e a muitos trabalhos como os realizado por Molle (1994), Campos (1997, 2000, 2003), Assunção e Liviggstone (1993), Malvera et al (2007), Suassuna (1993), Aragão e Oliveira (2011), Silans (2003), Pereira e Curi (2013) que discutem o tema e defendem ambos os lados.

Um dos argumentos de quem defende a pequena açudagem é que os grandes reservatórios perdem muita água por evaporação, além disso, os pesquisadores que a defendem alegam que não demanda de tanto investimento financeiro público como os grandes açudes, logo, é uma estratégia mais econômica. Molle (1994) corrobora essa ideia, afirmando que os pequenos açudes não têm gastos com desapropriação e manutenção, visto que, cabe aos proprietários gerenciar os mesmos.

No contexto dos pequenos e médios açudes, estima-se uma taxa de evaporação de cerca de $40 \%$ no período de estiagem em anos de precipitação normal. Nesse ritmo, um açude, por exemplo, com $100 \mathrm{mil} \mathrm{m}^{3}$ de água armazenada durante o período chuvoso perde até 15 mil $\mathrm{m}^{3}$ de sua lâmina de água por evaporação logo no início do período de estiagem (SILANS, 2003). Portanto, isso compromete a eficiência desse reservatório quanto a oferta de água durante o período de estiagem.

Outro fato que se coloca em debate é a utilização da água para múltiplos fins. Segundo Assunção e Livigstone (1993) os açudes têm sido subaproveitados para promover atividades produtivas como agricultura, piscicultura e criação de gado; sendo, realmente utilizados apenas em período de longas estiagens (plurianual).

Já os pequenos açudes funcionam "como importantes marcos sinalizadores para a organização produtiva e, principalmente, cultural" das comunidades rurais (ARAGÃO E OLIVEIRA, 2011, p. 40). Os autores afirmam ainda que, apesar da baixa eficiência de regularização dos pequenos açudes, estes devem ser considerados nas políticas de gestão devido a sua importância no atendimento das necessidades das populações nordestinas, além de participar diretamente no processo produtivo local. 
Dimensionamento e gestão de reservatórios: breve discussão acerca da experiência do estado do Ceará/Brasil

Sulivan Pereira Dantas

Um fato que prejudica a utilização mais eficiente dos grandes açudes e dos rios que foram perenizados por eles, é que estas áreas são de posse de grandes proprietários de terras que dificultam a desapropriação para poder gerar projetos de irrigação, por exemplo (FAO/World Bank, 1983 apud ASSUNÇÃO e LIVIGSTONE, 1993).

Também como argumento contra os grandes reservatórios os autores Assunção e Livigstone (1993), e Molle (1994) colocam que a única vantagem a favor dos mesmos é que estes servem para o abastecimento em períodos de longa estiagem, porém, os autores afirmam que "O fornecimento de água de última instância mediante uma combinação de grandes açudes e caminhões-tanque foi feito em quantidades muito pequenas, insignificantes quando comparadas ao volume acumulado disponível” (ASSUNÇÃO e LIVIGSTONE, 1993, p.15). Os autores ainda colocam que uma rede de cisternas seria mais eficiente que os grandes açudes.

Em contrapartida, os defensores da grande açudagem colocam em questão que os pequenos reservatórios são incapazes de oferecer suprimento em caso de secas que se prologuem por mais de um ano. Segundo Campos (1997) se a profundidade média do barramento for igual à lâmina evaporada, a capacidade de regularização interanual é inexistente, sendo assim, não ajuda a minimizar a vulnerabilidade da região à seca.

Levando em consideração que grande parte dos rios do Nordeste são intermitentes e que em praticamente metade do ano esses rios ficam "secos", logo os pequenos reservatórios ficam sujeitos à imprevisibilidade do escoamento e das chuvas (CEARÁ, 2008). Há então a necessidade de construir barramentos que tenham capacidade de acumulação igual ao volume médio escoado pelo mesmo para que se possa ter uma regularização interanual (CAMPOS, 1997).

Outro ponto a verificar é a interferência entre os açudes, pois, como já dito, os barramentos de pequeno porte são feitos, de modo geral, por iniciativa particular sem estudos aprofundados a cerca do impacto e localização dos mesmos. Quando esses barramentos são feitos a montante de um grande açude podem provocar a perda de eficiência do último.

Estudos realizados por Campos et al (2003) demonstra, em análise estatística feita com 40 reservatórios no vale do Rio Jaguaribe, que em média, os grandes reservatórios são mais eficientes que os pequenos. Além disso, mostra que a existência de pequenos açudes a montante prejudica o volume de regularização dos grandes açudes. Em estudo realizado por Studart et al (2005, p. 15) foi possível observar que:

Açude Várzea do Boi regularizava, sem a interferência dos reservatórios, um volume anual de 7,4 hm³/ano. Ao adicionar-se os pequenos reservatórios a 


\section{Dimensionamento e gestão de reservatórios: breve discussão acerca da experiência do estado do Ceará/Brasil}

Sulivan Pereira Dantas

sua montante, sua vazão regularizada individual passa para $4,4 \mathrm{hm} 3 / \mathrm{ano}$. Tal diferença não é suprida pelas vazões regularizadas individualmente por cada reservatório que, juntas, somam apenas $1,03 \mathrm{hm} 3 /$ ano. Os resultados apontam uma redução da ordem de $40 \%$ nas vazões regularizadas pelo reservatório, devido à pequena açudagem a montante.

Campos et al (2003) comprovam que a eficiência dos açudes de grande capacidade é maior em relação ao fator adimensional de evaporação. Esse fator leva em consideração a lâmina de água evaporada, a forma do reservatório e o deflúvio médio afluente anual. Os pequenos reservatórios regularizam, "em média, 23\% de deflúvio médio anual e evaporam $18 \%$ de deflúvio médio anual. Os grandes reservatórios têm um desempenho muito melhor; em termos médios, regularizam 33\% de deflúvio médio anual e evaporam apenas $7 \%$ de deflúvio médio anual.".

Campos (1997, p. 294) pontua elementos de vantagens e desvantagens a cerca da açudagem de pequeno e grande porte:

1) Para fins de regularização interanual, os grandes açudes, por terem um fator adimensional de evaporação mais baixo, são mais eficientes que os pequenos açudes;

2) os pequenos açudes, localizados próximos às cabeceiras dos rios, são, em geral, incapazes de resistir a secas mais prolongadas; a estes deve caber somente o papel de regularização intra-anual;

3) os pequenos açudes constituem-se na única possibilidade do aproveitamento das terras próximas às nascentes dos rios; a estes cabem o papel de distribuidor espacial do recurso água; entretanto, paga-se um alto preço em perdas por evaporação;

4) a disseminação descontrolada de açudes de pequeno porte a montante dos grandes açudes resulta em redução da capacidade de regularização dos grandes açudes, e, muitas vezes, na redução da eficiência de todo o sistema; e

5) o papel de reservas estratégicas de águas só deve caber aos grandes açudes; a esses devem ser atribuídas regras compatíveis com a segurança que deve ser atribuída a essas obras.

No quadro abaixo é possível visualizar as principais vantagens e desvantagens da pequena e da grande açudagem, considerando o ambiente semiárido:

Quadro 1: Quadro comparativo das vantagens e desvantagens das dimensões dos reservatórios para o semiárido.

\begin{tabular}{|c|c|c|}
\hline & Pequena açudagem & Grande açudagem \\
\hline Vantagens & $\begin{array}{l}\text { - Baixo custo de construção e } \\
\text { manutenção; } \\
\text { - Fácil acesso para pequena } \\
\text { agricultura e pecuária; } \\
\text { - Única forma de aproveitar as } \\
\text { águas próximas as nascentes; }\end{array}$ & $\begin{array}{l}\text { - Regulação interanual; } \\
\text { - } \text { Menor perda de água por } \\
\text { evaporação; } \\
\text { - Fonte segura de água em } \\
\text { períodos de longa estiagem; }\end{array}$ \\
\hline Desvantagens & $\begin{array}{l}\text { - Incapacidade de regularização } \\
\text { interanual; }\end{array}$ & $\begin{array}{l}\text { - Alto custo de construção e } \\
\text { manutenção; }\end{array}$ \\
\hline
\end{tabular}


Dimensionamento e gestão de reservatórios: breve discussão acerca da experiência do estado do Ceará/Brasil

Sulivan Pereira Dantas

\begin{tabular}{|l|l|l|}
\hline & $\begin{array}{l}\text { Grandes perdas de água por } \\
\text { evaporação; }\end{array}$ & $\begin{array}{l}\text { Alto custo para a distribuição } \\
\text { da água em períodos de } \\
\text { estiagem (carros-pipa). }\end{array}$ \\
$\begin{array}{l}\text { Má localização que prejudica a } \\
\text { eficiência de açudes a sua } \\
\text { jusante; }\end{array}$ & $\begin{array}{l}\text { Sub-aproveitamento devido à } \\
\text { dificuldade de acesso a água; }\end{array}$ \\
\hline
\end{tabular}

Fonte: Adaptado de Campos (1997) e Assunção e Livigstone (1993).

Porém, diante do que foi evidenciado ressalta-se que é essencial que em ambos os barramentos se faz necessário um estudo mais detalhado para sua implementação e para o seu uso. O debate permanece vigente devido, principalmente, a questão de eficiência das águas redimensionadas. Isso implica diretamente no processo de gerenciamento local.

\section{Os desafios da gestão e do monitoramento de reservatórios no semiárido brasileiro: acerca da experiência do estado do Ceará}

O estado do Ceará tem registrado uma preocupação crescente com a gestão e monitoramento dos recursos hídricos, especialmente com os reservatórios. Várias alternativas de gerenciamento vêm sendo implementadas buscando a eficiência do controle de água, como a criação dos comitês de bacias.

Com a inserção de novas necessidades, o Estado cria estruturas de abastecimento de água, consequentemente novos investimentos do capital privado são implantados, gerando cada vez mais demanda e tornando-se necessário o estabelecimento de novas políticas aptas a se encarregarem do gerenciamento das águas. Apontando o Ceará como um dos poucos estados do Norte/Nordeste brasileiro com sua política de recursos hídricos efetivada, a partir de uma gestão controlada no local.

Para se referir ao tema recursos hídricos, Nascimento (2004, p. 11) comenta que:

[...] por conta da crescente demanda por água ao consumo humano e para as atividades produtivas, há que se adequar a relação água/sociedade (cada habitante da bacia hidrográfica) ao processo de gerenciamento integrado da água, a qual Rebouças (1997) chamou de disponibilidade hídrica social nos rios porque à proporção que a demanda por água aumenta, alcançando determinados níveis de disponibilidades sociais - disponibilidades per capita - a demanda por gerenciamento é fundamental.

Nesse contexto, a partir da década de 80 o Estado passa a se preocupar com a organização do setor de recursos hídricos institucional, buscando amenizar a convivência traumática com o fenômeno das secas. A criação da Secretaria dos Recursos Hídricos - SRH, da Superintendência de Obras Hidráulicas - SOHIDRA, a aprovação da Lei Estadual de Recursos Hídricos No 11996 de 24/07/1992, a criação da Companhia de Gestão dos Recursos Hídricos - COGERH e o monitoramento de tempo e do clima realizado pela Fundação 
Dimensionamento e gestão de reservatórios: breve discussão acerca da experiência do estado do Ceará/Brasil

Sulivan Pereira Dantas

Cearense de Meteorologia e Recursos Hídricos - FUNCEME fazem parte da política de estruturação da gestão hídrica estadual.

No entanto, percebe-se que os desafios da gestão hídrica do Ceará permanecem na insuficiência da consolidação da integração interinstitucional. Levando em conta a experiência desenvolvida na região e o acervo de conhecimento desenvolvido ao longo dos anos pode-se listar os principais desafios relacionados à gestão e monitoramento de reservatórios no estado:

- Segurança das obras hídricas realizadas;

- Integração interinstitucional;

- O uso da água como bem econômico e social;

- Monitoramento hidroclimático dos reservatórios e do entorno;

- Instrumentalização institucional e tecnológica;

- Capacitação e valorização do quadro de funcionários;

- Gestão participativa eficiente;

- Sistema de alerta para desastres naturais e eventos extremos;

- Política permanente de racionamento de água.

Esses são alguns dos desafios básicos que os gestores de água enfrentam no Estado do Ceará, buscando na perspectiva regional a sustentabilidade hídrica. Tendo em vista ao que foi mencionado, paralelamente à infraestrutura hídrica observada no estado, é imprescindível fortalecer o uso e reuso da água por meio de políticas de racionamento.

Essas políticas devem atender a necessidade do desenvolvimento econômico local e regional sem eximir os pontos permanentes das pequenas propriedades rurais, $\mathrm{o}$ abastecimento humano e animal. Pois, geralmente, os pequenos projetos de irrigação e criação de animais são os primeiros a sofrer as consequências das secas. Portanto, devem-se diminuir os desperdícios não só da agricultura irrigada como também nos abastecimentos públicos das grandes cidades; atentar ao uso e reuso da água; monitoramento da qualidade das águas dos reservatórios e dos processos de poluição das águas; conservação das nascentes a fim de garantir recarga hídrica periódica e etc.

O grande número de barramentos no Estado do Ceará é reflexo das peculiaridades climáticas e geológicas que inferem alto poder de escoamento e, portanto, deficiência de acumulação hídrica nas bacias. Segundo dados da Cogerh (2020) o estado do Ceará conta com mais de seis mil reservatórios em todas as suas dimensões. Vale ressaltar que apenas 153 açudes são monitorados pela Companhia, considerando esse mais um desafio da gestão de 
Dimensionamento e gestão de reservatórios: breve discussão acerca da experiência do estado do

reservatórios no Ceará, em fortalecer e ampliar o controle e o monitoramento de açudes que se encontram no território cearense.

No âmbito dos atuais conhecimentos sobre o planejamento e o gerenciamento dos recursos hídricos, o assunto deve ser analisado a partir do entendimento de que pequenos e grandes açudes são, em devidas proporções, obras de infraestrutura hídrica de grande contribuição para a sociedade e meio ambiente. Portanto, torna-se de suma importância o estudo da dinâmica das águas que o semiárido cearense vem vivenciando, sendo papel do estado e da sociedade civil zelar pelo o bem comum a todos, a água.

Baseando-se pela ordem de classificação da Cogerh (2008), de acordo com o critério da capacidade volumétrica do reservatório, os açudes podem ser classificados em macro porte (> que 750.000.000 $\mathrm{m}^{3}$ ); grande porte (de 75.000 .000 a $750.000 .000 \mathrm{~m}^{3}$ ); médio porte (de 7.500 .000 a $75.000 .000 \mathrm{~m}^{3}$ ); e de pequeno porte (de 0.5 a $7.500 .000 \mathrm{~m}^{3}$ ). Neste trabalho apresentam-se os 15 maiores reservatórios do estado do Ceará (Figura 1), baseados no critério de classificação da Cogerh, classificados como açudes de grande e macro porte. 
Dimensionamento e gestão de reservatórios: breve discussão acerca da experiência do estado do Ceará/Brasil

Sulivan Pereira Dantas

Figura 01: Mapa dos reservatórios de macro e de grande porte do estado do Ceará

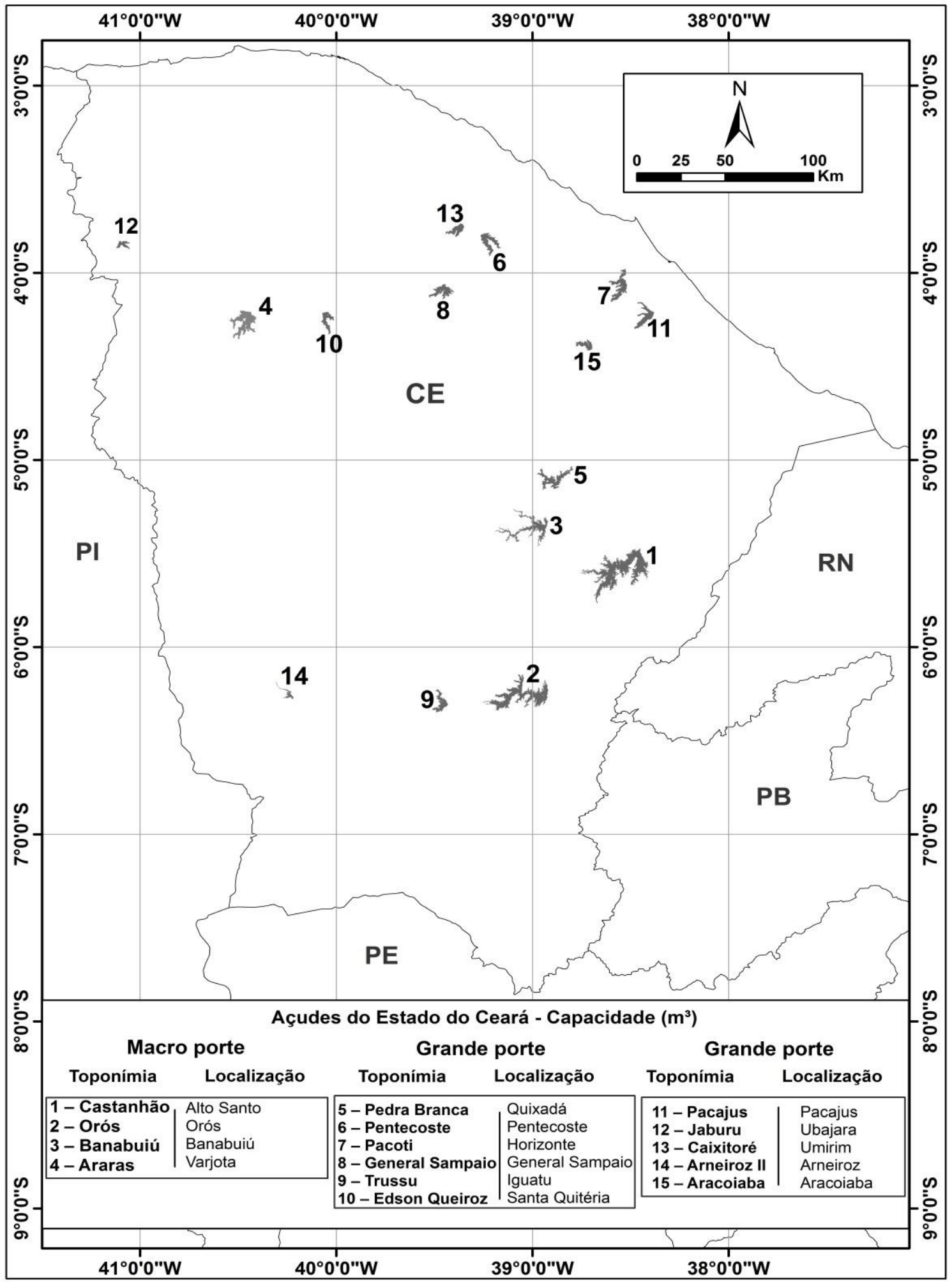

Fonte: Elaborado pelo autor (2020).

Percebe-se que o Ceará apresenta uma ampla infraestrutura hídrica, concentrandose principalmente no vale do Jaguaribe. O rio Jaguaribe no Ceará representa a maior fonte de recursos hídricos do Estado (CAVALCANTE e CUNHA, 2009). Com cerca de $74.000 \mathrm{~km}^{2}$ de 
Dimensionamento e gestão de reservatórios: breve discussão acerca da experiência do estado do Ceará/Brasil

Sulivan Pereira Dantas

bacia hidrográfica e $610 \mathrm{~km}$ de extensão, este já foi considerado o maior rio seco do mundo, estando atualmente fortemente regularizado por um grande número de barragens de pequeno, médio e grande porte. Contudo, o desafio do fortalecimento dessa política é de fato o gerenciamento e monitoramento pequeno, médio e grande porte, onde se destaca a barragem do Castanhão, localizada no médio curso deste rio, representando a maior garantia do Estado hoje.

\section{CONSIDERAÇÕES FINAIS}

A construção de barragens sobre o território nordestino tornou-se uma das políticas de convivência com a seca, devido, principalmente, pela alta vulnerabilidade da região, pois a mesma apresenta solos rasos em grande parte do seu território, com rochas bastantes aflorantes que comprometem tanto a recarga hídrica como a qualidade da água, altas temperaturas que conduzem a altas taxas de evaporação, além da concentração em sua maior parte de rios intermitentes e alto índice de concentração populacional, acarretando pressões sobre os recursos hídricos da região.

Considerando as características da Região e os problemas acarretados devido ao fenômeno da seca pode-se afirmar que, sem dúvidas, a política de combate às longas estiagens foi, quase que em sua totalidade, pautada na açudagem.

A politica de açudagem no Nordeste brasileiro tem contribuindo, substancialmente, sobre os impactos da seca sobre a população, reduzindo o número de mortos e famintos em caso de grandes estiagens. Além disso, o processo de açudagem associado à política de desenvolvimento do Nordeste trouxe tanto uma infraestrutura física (rodovias, açudes, adutoras, etc.), quanto intelectual, com o incentivo a pesquisas nas Universidades Públicas visando compreender melhor as características naturais do Nordeste e desenvolver modos de conviver com tais.

Com o desenvolver dos estudos e a grandiosidade que se tornou a açudagem, tanto pela quantidade de barragens como pela capacidade de armazenamento das mesmas começaram-se, então, os questionamentos sobre a eficiência dessas obras, principalmente, os vultosos investimentos feitos com os grandes açudes. É certo que a construção de reservatórios é essencial para garantir o abastecimento de água em longos períodos de seca, contudo, é preciso aprimorar o gerenciamento destes. Para realizar o uso sustentável das águas represadas é necessário haver uma parceria entre o poder público e a sociedade civil, a fim de garantir segurança hídrica a todos que convivem com a realidade do semiárido nordestino brasileiro. 
Dimensionamento e gestão de reservatórios: breve discussão acerca da experiência do estado do Ceará/Brasil

Sulivan Pereira Dantas

\section{Referências}

ARAGÃO, D. A.; OLIVEIRA, J. G. B. Gestão de recursos hídricos: aspectos da pequena açudagem na gestão de sub-bacias no Ceará. Engenharia Ambiental - Espírito Santo do Pinhal, v. 8, n.2, p.038-049, abr. /jun. 2011.

ASSUNÇÃO, Luiz Márcio; LIVIGSTONE, Ian. Desenvolvimento inadequado: construção de açudes e secas do Nordeste. Revista Brasileira de Economia, Rio de Janeiro, 1993.

CAMPOS, José Nilson Bezerra. Vulnerabilidades hidrológicas do semi-árido às secas. Planejamento e políticas públicas, n. 16, 1997. Disponível em: <http://www.ipea.gov.br/ppp/index.php/PPP/article/view/120>. Acesso em: 28 jul. 2015.

. A evolução das políticas públicas no Nordeste. In: CCGE- Centro de Gestão e Estudos Estratégicos. A Questão da Água no Nordeste. Agência Nacional de Águas. Brasília, DF: CGEE, 2012.

Secas e políticas públicas no semiárido: ideias, pensadores e períodos. Revista sociedade e ambiente, estudos avançados, v. 28, n. 82, São Paulo, 2014. Disponível em: <http://www.scielo.br/scielo.php?pid=S010340142014000300005\&scri pt=sci_arttext $>$. Acesso em: 28 jul. 2015.

; et al. Contribuições ao debate sobre a eficiência de pequenos e grandes reservatórios. Revista Brasileira de Recursos Hídricos- RBRH. v. 8, n. 2, 2003. Disponível em: $\quad<$ https://www.abrh.org.br/sgcv3/UserFiles/Sumarios/b6f57934549Ffbe adfb806a384e992db_0e6a53e4336804aa3ecca7856daf5f62.pdf>. Acesso em: 28 jul. 2015.

CAVALCANTE, A. A. CUNHA, S. B. da. Caracterização do sistema fluvial do rio Jaguaribe no semi-árido cearense. XVIII Simpósio Brasileiro de Recursos Hídricos. Campo Grande, MS, 2009.

CEARÁ. Cenário atual dos recursos hídricos do Ceará. Fortaleza: INESP (Coleção Pacto das Águas), 2008.

COGERH. Rede de Monitoramento operada pela COGERH. 2008. Disponível em: http://www.funceme.br/areas/monitoramento/nivel-diario-de-reservatorios. Acesso em: 03 jun. 2014.

DNOCS. Conferências: visões do semiárido por dirigentes do DNOCS. Fortaleza: DNOCS/BNB, 2010.

MACEDO, Maria Vilalba A. de. Aproveitamento Hídrico das Bacias Fluviais do Ceará. Fortaleza, DNOCS, 1981. 176 p.

MOLLE, François. Marcos históricos e reflexões sobre a açudagem e seu aproveitamento. Recife: SUDENE, 1994. 
Dimensionamento e gestão de reservatórios: breve discussão acerca da experiência do estado do Ceará/Brasil

Sulivan Pereira Dantas

MONTEIRO, Carlos Augusto de Figueiredo. O estudo geográfico do clima. Cadernos de Geografia. Florianópolis, ano I, n 1, 1999.

NASCIMENTO, Maria Anezilany Gomes do. Nem parece o tempo em que vocês jogavam biriba na calçada: o lugar em Nova Jaguaribara. Dissertação de Mestrado. Fortaleza: UECE, 2004.

SILVA, Roberto Marinho Alves da. Entre o combate à seca e a convivência com o semiárido: políticas públicas e transição de paradigmas. Revista Econômica do Nordeste, Fortaleza, v. 38, n. 3, 2007.

SILANS, ALAIN M. B. P. de. Redução de evaporação de açudes - o estado da arte. Revista Brasileira de Recursos Hídricos, volume 8, n 2. João Pessoa: RBRH, 2003. Pág. 101 - 109.

SUASSUNA, JOÃO. A pequena e média açudagem no semiárido nordestino: uso da água para produção de alimentos. Fundação Joaquim Nabuco. Recife, 1993.

STUDART, T.M.C.; et al. Democratização na distribuição espacial de água no nordeste semiárido e a eficiência hidrológica de um sistema de reservatórios superficiais. Congresso ABRH, 2005. Disponível em: <http://www.barramentos.ufc.br/Hometiciana/Arquivos/Publicacoes/Congressos/2005/ABRH _2005_vboi_artigo_20\%20de\%20junh_def2.pdf>. Acesso em: 10 set. 2015.

SUDENE. Contribuição da SUDENE ao desenvolvimento do Brasil. Disponível em: <http://www.sudene.gov.br/sudene>. Acesso em: 28 jul. 2015.

VIEIRA, Vicente P. P. B. Desafios da gestão integrada de recursos hídricos no semi-árido. Revista Brasileira de Recursos Hídricos- RBRH, v. 8, n 2, 2003.

COGERH. Rede de Monitoramento operada pela COGERH. 2008. Disponível em: http://www.funceme.br/areas/monitor amento/nivel-diario-de-reservatorios. Acesso em: 03 jun. 2014. 